Finisterra, XXXVI, 71, 2001, pp. 143-145

\title{
REESTRUTURAÇÃO E EXPANSÃO INDUSTRIAL DA ÁREA METROPOLITANA DE LISBOA. A EMERGÊNCIA DE NOVOS TERRITÓRIOS: OS CASOS DE SINTRA E ALENQUER
}

HeIToR Gomes ${ }^{1}$

Nos dois últimos decénios, os efeitos de um intenso processo de reestruturação produtiva no espaço europeu levaram a uma aparente interrupção na expansão industrial contínua que os territórios metropolitanos conheciam até então. Muitos autores consideraram a problemática da desindustrialização metropolitana como uma consequência inevitável do processo de terciarização dos espaços urbanos e das sociedades, pondo fim a um período em que a indústria se revelava o motor da urbanização e do crescimento económico mundial.

Contudo, as pretensões segundo as quais as economias das grandes cidades teriam ultrapassado, de uma ou outra forma, a sua base económica suportada pela indústria, caminhando para uma fase pós-industrial, revelaram-se prematuras, visto assistir-se ao explanar de novas formas de concentração da produ-ção, não compatíveis com os modelos anteriores e que resultaram na revitalização dos espaços metropolitanos. Com efeito, as aglomerações metropolitanas dos países capitalistas tornam-se locais de optimização das funções produtivas e da sua articulação por complexas redes e fluxos, em que se fundamentam os modernos paradigmas da flexibilidade.

O desenvolvimento do processo de reestruturação produtiva surte importantes efeitos na geografia, resultando na emergência de novos modelos territoriais, suportados em novas estruturas de organização económica do espaço, dando um renovado protagonismo às questões cada vez mais complexas da localização industrial.

Todo o conjunto de alterações recentes anteriormente enunciado é também observado, apesar de claros desfasamentos temporais em alguns processos, em Portugal, particularmente no território economicamente mais competitivo do país: a Área Metropolitana de Lisboa. Estas mudanças contribuíram decisivamente para o levantar de novas questóes no quadro industrial metropolitano de Lisboa. Os paradigmas espaciais emergentes, marcados pelos efeitos contraditórios do processo de reestruturação (das áreas em declínio à expansão peri-férica) são uma vertente de profundo interesse de investigação,

1 Geógrafo, Email: Heitor.Gomes@mail.pt 
no sentido de procurar clarificar as razões que se encontram na base de tais transformações.

O trabalho de investigação desenvolvido na dissertação de mestrado «Reestruturação e Expansão Industrial da Área Metropolitana de Lisboa. A Emergência de Novos Territórios: os Casos de Sintra e Alenquer» ${ }^{2}$ procura, assim, constituir um contributo para o estudo do processo de reestruturação industrial da Área Metropolitana de Lisboa (AML), procurando primacialmente discutir os paradigmas espaciais surgidos nos últimos anos, suportados em novas $\begin{array}{lllllllllll}e & s & t & r & u & t & u & r & a & s\end{array}$ de organização económica do espaço, que se caracterizam por movimentos tendentes de desconcentração e expansão periférica do sector produtivo.

A análise de duas áreas industriais em pormenor - Abrunheira-Alto do Forte-São Carlos, em Sintra e Carregado, em Alenquer - revela-se o suporte central para procurar compreender e clarificar as razões que justificam o dinamismo recente evidenciado na indústria em determinados territórios, com ca-racterísticas e localizações diferentes, no contexto intra e suprametropolitano, enquanto que simultaneamente outros espaços industriais entram em declínio.

A dissertação encontra-se estruturada em cinco capítulos, divididos em três partes: enfoque teórico - a geografia industrial em mudança; industrialização e reestruturação industrial na Área Metropolitana de Lisboa; a emergência de novos territórios - os casos de Sintra e Alenquer. O Capítulo I serve de introdução ao estudo, incidindo sobre os aspectos teóricos que envolvem a evolução epistemológica da temática da geografia industrial e os paradigmas emergentes nesta disciplina. No Capítulo II, é dada particular atenção às questões relacionadas com os processos de reestruturação industrial nos espaços metropolitanos e os processos de organização do espaço produtivo e transformações recentes. Neste capítulo são também afloradas as grandes alterações no sistema económico mundial após o período pós-guerra até à actualidade. O Capítulo III incide fundamentalmente na análise da génese da industrialização moderna na Área Metropolitana de Lisboa, considerando-se uma vez mais, em termos temporais, o período pós-guerra. Procura-se igualmente extrapolar a importância industrial da AML no contexto de Portugal, comparando-a com o restante território nacional. No Capítulo IV é realizada uma abordagem ao processo de reestruturação industrial na AML nas duas últimas décadas, inserindo a área de estudo no quadro industrial nacional,

2 Dissertação de mestrado em Geografia Humana e Planeamento Regional e Local, apresentada à Faculdade de Letras da Universidade de Lisboa em 2001, sob a orientação do Prof. Dr. Mário Vale, desenvolvida com o apoio da Fundação para a Ciência e Tecnologia (FCT), Programa PRAXIS XXI; do projecto de investigação «Divest - Desinvestimento e Impactes Económicos, Sociais e Territoriais» (Projecto POCTI/34037/GEO/2000 - FCT); British Council e Instituto de Cooperação Científica e Tecnológica Internacional. 
procurando verificar de que modo este processo de reestruturação influenciou o aparecimento de novas áreas industriais no seu interior e na sua periferia. Finalmente, no Capítulo V procede-se ao desenvolvimento dos casos de estudo, discutindo-se os factores locativos que se encontram na base da emergência e desenvolvimento industrial destes espaços, utilizando como principal instrumento a análise de informação resultante de um exaustivo trabalho de recolha directa.

As principais conclusões desta dissertação permitem-nos referir, principalmente, que as transformações recentes são marcadas por um crescimento industrial na região metropolitana, visível, sobretudo, nos espaços periféricos da AML. Do encadeamento resultante deste processo, observa-se a emergência de novos modelos territoriais, suportados por inovadoras estruturas da organização económica do espaço, que se reflectem nos efeitos contraditórios gerados pelos mecanismos de crescimento e de reestruturação industrial.

A modelização da estrutura industrial metropolitana em Lisboa em finais do séc. $\mathrm{XX}$, encaminha-se para um modelo idêntico ao das principais metrópoles internacionais, inquestionavelmente mais complexo e disperso do ponto de vista espacial, em que um dos aspecto mais marcantes das transformações recentes se prende, paradoxalmente, com o facto dos centros de decisão, do efeito catalisador, do ambiente inovador e dos serviços essenciais de ordem superior continuarem concentrados no espaço intra-metropolitano, principalmente em Lisboa.

Por último, a análise do estudo de casos permitiu verificar que o sucesso recente de determinados territórios industriais enquadrados no sistema metropolitano, se deve a um conjunto alargado de factores de localização, de acordo com as características das empresas que em cada área industrial se vão instalar. Torna-se imperativo, todavia, ressaltar como aspectos determinantes na lógica locativa, a importância acrescida que as acessibilidades; o custo e disponibilidade de terreno; o custo e disponibilidade da mão-de-obra; e a proximidade ou inserção na AML (o maior mercado consumidor do país) desempenharam no processo de decisão final da localização das empresas. 